\title{
Viral exploitation and subversion of the immune system through chemokine mimicry
}

Philip M. Murphy

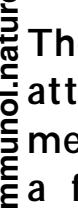

he chemokine superfamily of leukocyte chemoattractants coordinates development and deployment of the immune system by signaling through a family of $G$ protein-coupled receptors. The importance of this system to antimicrobial host defense has been supported by the discovery of enumerous herpesviruses and poxviruses that encode chemokine mimics able to block chemookine action. However, specific herpesviruses and lentiviruses can also exploit the immune system through chemokine mimicry, for example, to facilitate viral dissemination or, as in the case of IIV-1, to directly infect leukocyte target cells. 2 The study of viral mimicry of chemokines and chemokine receptors is providing important new concepts in viral immunopathogenesis, new antiinflammatory drug leads and new targets and concepts for antiviral drug and vaccine development.

To an immunologist, the chemokine signaling system appears primarily to coordinate development and deployment of the immune system and, therefore, to support antimicrobial host defense $\mathrm{e}^{1,2}$. However, it is now clear that viruses have thoroughly corrupted this system through molecular mimicry, using it as a toolbox for facilitating diverse steps in pathogenesis. The chemokine system consists of at least 50 structurally related peptide agonists and $20 \mathrm{G}$ protein-coupled receptors. To date, more than 30 distinct virally encoded chemokine and chemokine receptor mimics have been identified, all in the herpesvirus, poxvirus and retrovirus families. These include six medically important viruses: HIV; human cytomegalovirus; human herpesviruses 6, 7 and 8; and molluscum contagiosum virus. Because immunosuppressed subjects can be coinfected with several of these viruses, it follows that the chemokine mimics produced by each virus might interact in a pathophysiologically significant manner not only with the host chemokine system but also with the chemokine mimics encoded by the other viruses (Fig. 1).

One subset of mimics includes actual chemokines and chemokine receptors, which were presumably acquired by the virus in the manner of viral oncogenes, by gene transfer from the host. The captured sequences can be spliced or unspliced ${ }^{3,4}$ and are clear examples of divergent evolution. A second subset includes molecules with structures that are unrelated to chemokines or chemokine receptors, but which bind to either a chemokine or a chemokine receptor, thus distorting its function. These are examples of convergent evolution. The chemokine and chemokine receptor mimics form the largest known class of viral homologs of host proteins. The majority of the others are mimics either of other types of immunoregulatory molecules or of cell-cycle-control proteins ${ }^{5,6}$.

To date, the most important achievement in this area has been to define a central role for the chemokine receptor CCR5 in HIV pathogenesis ${ }^{7,8}$. This has enabled new antiretroviral drug and vaccine development strategies that have the unusual feature of exploiting a host protein ${ }^{9,10}$. Additional chemokine mimics have direct potential as anti-inflammatory agents. In this review I will first present a classification system for viral chemokine mimics (Table 1), then focus on recent advances and important unanswered questions with an emphasis on molecules relevant to HIV disease.

\section{Classification of viral chemokine mimics}

Chemokine mimics can be classified into three groups according to their structure: chemokine homologs; chemokine receptor homologs; and unique structures not related in primary amino acid sequence to either chemokines or chemokine receptors (Table 2). Viral chemokine homologs are defined solely by structural similarities. In contrast, because chemokine receptors are related structurally to other types of $\mathrm{G}$ protein-coupled receptors, they are defined by functional criteria (chemokine binding and signal transduction).

Viral chemokine homologs are found mainly in herpesviruses and include both CC and CXC chemokines, the two main divisions of the chemokine superfamily. Unlike most herpesvirus genes, the genes encoding chemokine and chemokine receptor homologs are often not conserved by closely related herpesviruses. This suggests that they may regulate unique aspects of pathogenesis.

The six known viral chemokine receptors all bind multiple chemokine ligands but differ from each other with respect to specific signaling properties and chemokine specificity. The ligand specificities for these receptors are unusually diverse and, in some cases, even cross the subclass boundaries that govern the mammalian receptors. The receptors have $25-59 \%$ amino acid sequence identity to mammalian chemokine receptors as well as shared structural features such as an acidic $\mathrm{NH}_{2}$-terminus and a short basic third-intracellular loop that are characteristic of, but not invariant among or exclusive to, vertebrate chemokine receptors. Additional candidate chemokine receptors have been identified based on high sequence homology with known chemokine receptors. In some cases the candidate open-reading frame (ORF) is syntenic with a known chemokine receptor ORF in a related virus.

To date, five distinct subclasses of mimics have been identified according to in vitro functions: anti-chemokines; cell-entry factors; cellgrowth factors; angiogenic factors; and leukocyte chemoattractants. 


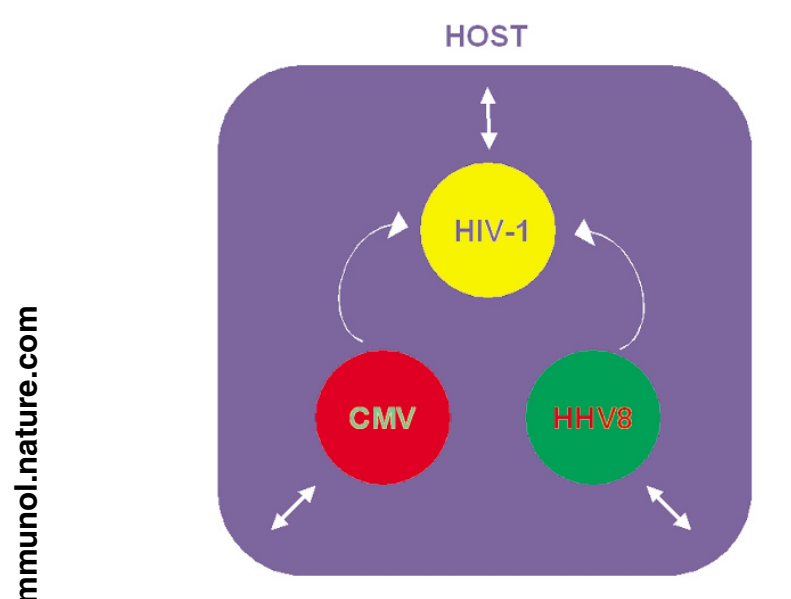

Figure 1. Potential combinatorial effects of chemokine mimicry on viral immunopathogenesis. Immunosuppression, such as that caused by HIVAIDS, may promote productive coinfection of the same host (blue box) with CMV, HHV8 and other herpesviruses as well as the poxvirus molluscum contagiosum virus. Both host and virus may deploy chemokine mimics that, in some cases, have been shown, in vitro, to interact with those of the other viruses and of the host (arrows). Reported interactions include the ability of the CMV-encoded chemokine receptor US28 to support HIV infection by functioning as an HIV coreceptor and the ability of the HHV8 chemokine mimic VMIP-II to block both that activity as well as HIV-1 usage of the host leukocyte receptors CCR5 and CXCR4. Host chemokines can also block gp120 usage of host chemokine receptors for $C D 4^{+}$target-cell entry. 0 ther viral chemokine mimics can act as agonists (o chemokine receptors, possibly to promote viral dissemination. Interaction of HIV-1 gp120 with C CR5 is critical for efficient HIV transmission in exposed populations. W hether other potential interactions among viral mimics occur in vivo and affect pathogenesis is not yet known.

(2) Anti-chemokines subvert the immune system, whereas other types of mimics exploit it. Anti-chemokines can be further subclassified into - three groups according to structure and mechanism of action: chemokine homologs that act as chemokine receptor antagonists; chemokine receptor homologs that function as plasma membraneexpressed chemokine scavengers; and chemokine binding proteins with signal sequences, which may have unique and unrelated structures and which function as secreted chemokine scavengers.

Each mimic may carry out more than one function and each function may be carried out by mimics from more than one structural class. Of the 13 known herpesvirus and poxvirus chemokine homologs, five are agonists, two are antagonists and six are still functionally undefined. Six are CC chemokines and seven are CXC chemokines. Viral chemokine agonists act in vitro as leukocyte chemoattractants of narrow specificity, possibly to focus preferred host cells at the site of infection and ensure viral spread.

\section{Chemokine mimicry by HIV-1 gp120}

The most notorious example of chemokine mimicry is gp120 of the HIV-1 envelope glycoprotein. gp120 lacks a chemokine structural fold and chemokine sequence motifs and yet can exploit specific chemokine receptors, known as HIV coreceptors, to enable infection of immune system targets ${ }^{7,8}$. HIV-2, SIV and other lentiviral envelope glycoproteins also do this. Whether this is the only significant activity of gp120 in vivo is not yet clear. In vitro soluble gp120 can also act at both CCR5 and CXCR4 to induce leukocyte signalling ${ }^{11-13}$. It can also act at CXCR4 to directly induce apoptosis of $\mathrm{CXCR}^{+}$neurons $^{14}$ and can indirectly induce apoptosis of $\mathrm{CD}^{+} \mathrm{CXCR} 4^{-} \mathrm{T}$ cells by stimulating tumor necrosis factor (TNF) release from macrophages ${ }^{15}$. Together these activities have major implications for how HIV may recruit, infect and deplete immune system cells.

The generally accepted model of HIV infection holds that gp 120 forms a trimolecular complex with CD4 and either CCR5 or CXCR4. This results in deployment of a cryptic fusogenic peptide of gp41, which induces fusion of the viral envelope with the plasma membrane of CD4 target cells $\mathrm{s}^{7,16}$. According to a widely used nomenclature system ${ }^{17}$, viruses that can use either of these coreceptors are designated R5X4, whereas monotropic strains are designated R5 (CCR5-using) or X4 (CXCR4using). Because homozygous inheritance of the defective allele CCR5 $\triangle 32$ - which encodes a truncated form of CCR5 not expressed on the plasma membrane - is strongly associated with HIV resistance in populations at risk for infection, normal CCR5 is, by implication, most likely required for efficient person-to-person HIV-1 transmission ${ }^{18-20}$. This, coupled with the lack of apparent health problems in CCR5 $\Delta 32$ homozygotes, has identified CCR5 as an attractive drug-development target. Several methods to block CCR5 have been published and potent small-molecule antagonists are already in early stages of clinical testing. The therapeutic efficacy of CCR5 blockade may differ for preventing infection as compared to slowing or preventing progression of established infection and could be limited by the ability of virus to evolve usage of other coreceptors, particularly CXCR ${ }^{21}$. The importance of CXCR4 in vivo is supported by the presence of pure X4 strains in approximately one-third of AIDS patients and rare CCR5 $\Delta 32$ homozygotes that are $\mathrm{HIV}^{+}$(ref. 22). However, it is also possible that the 13 or so other "minor" coreceptors identified so far using model systems also operate in disease and might threaten treatment strategies targeting CCR5 ${ }^{23}$. Biological evidence for this is limited to a small number of studies of blocking agents or naturally occurring genetic polymorphisms, which are so far inconclusive (CCR2, CCR3, CCR8) or conflicting (CX3CR1) ${ }^{24-28}$.

The structural basis of chemokine mimicry by gp120 is extremely complex and, despite the availability of a crystal structure ${ }^{29}$, not yet defined. Like chemokines, gp120 appears to bind to multiple low affinity sites on coreceptors, which together create a high binding energy. Some binding sites - for example, a sulfated tyrosine in the $\mathrm{NH}_{2}$-terminal segment ${ }^{30}$ also appear to bind chemokines, which explains why the two ligands cross-compete in binding studies. Nevertheless, different gp120s that recognize the same coreceptor can discriminate among other coreceptors and can even bind to different sets of extracellular domains of the same coreceptor $^{31}$. In addition, X4 and R5 tropism can be switched by changing the specificity of just a single basic amino acid within the V3 loop of gp $120^{32}$.

Efficient formation of the fusion complex requires sequential interaction of HIV-1 gp120 first with CD4, then with coreceptor ${ }^{33}$, which indicates that chemokine mimicry by gp120 is CD4-dependent. Several exceptions to this have been noted however ${ }^{7}$. Recent evidence from immunoprecipitation studies in primary $\mathrm{CD}^{+} \mathrm{T}$ cells, monocytes and macrophages indicates that CD4 binds constitutively to coreceptor monomers, possibly via the second extracellular loop, in the absence of gp $120^{34,35}$. However, there is, as yet, no hard evidence that this interaction modulates the normal signaling function of either CD4 or coreceptors. Chemokine ligands have been reported to induce dimerization of CCR2, CCR5 and CXCR4 ${ }^{36-38}$ and studies using an agonistic monoclonal antibody suggest that the CCR2 dimer is the signaling form of the receptor. However, coreceptor dimerization may actually inhibit rather than facilitate HIV fusion ${ }^{37}$. Still, if, as appears to be the case, the HIV envelope glycoprotein is a multimeric structure, it follows that multiple CD4-coreceptor complexes are likely to be recruited into the fusion complex.

Although when tested in reporter cell lines the specificity of HIV strains for CCR5 and CXCR4 is relatively clear, it does not always correlate with tropism for natural targets in primary cells and tissues. Whether this is due 
Table 1.Viral mimics of chemokines and chemokine receptors

\begin{tabular}{|c|c|c|c|c|c|}
\hline Virus family & Virus & ORF & $\begin{array}{l}\text { Common } \\
\text { names }\end{array}$ & $\begin{array}{l}\text { Chemokine or } \\
\text { receptor class }\end{array}$ & Function \\
\hline \multirow{10}{*}{$\gamma_{2}$ Herpesviridae } & \multirow{5}{*}{$\begin{array}{l}\text { Herpesvirus saimiri } \\
\text { HHV8 (KSHV) }\end{array}$} & 74 & ECRF3 & $E L R+C X C R$ & Calcium flux in vitro ${ }^{61}$ \\
\hline & & 74 & $\begin{array}{l}\text { ORF } 74 \\
\text { KSHV GPCR }\end{array}$ & $\begin{array}{l}\text { CC }-C X C R \\
\text { (constitutively active) }\end{array}$ & $\begin{array}{l}\text { Pro-inflammator } \mathrm{y}^{54,57} \text {; } \\
\text { angio genic }{ }^{103} ; \text { onco genic }{ }^{54}\end{array}$ \\
\hline & & K6 & VMIP-I & CC chemokine & Angiogenic ${ }^{4} ;$ C C R8 agonist ${ }^{66}$ \\
\hline & & K4 & VMIP-II & CC chemokine & 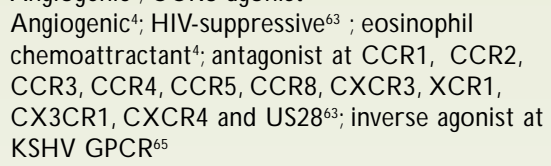 \\
\hline & & K 4.1 & VMIP-III & CC chemokine & $\begin{array}{l}\text { CCR4 agonist }{ }^{64} ; \text { angiogenic }{ }^{64} ; \mathrm{T}_{H} 2 \\
\text { cell chemotaxis }{ }^{64}\end{array}$ \\
\hline & \multirow{2}{*}{ Mouse $\gamma \mathrm{HV} 68$} & 74 & ORF 74 & Putative CXCR & NA \\
\hline & & M3 & M3 & $\begin{array}{l}C C, C, C X C \text { and } \\
C X 3 C \text { chemokine } \\
\text { binding protein }\end{array}$ & Broad spectrum chemokine scavenger 97,98 \\
\hline & \multirow[t]{3}{*}{ Equine HV2 } & E1 & E1 & CCR & Eotaxin receptor; chemotaxis ${ }^{104}$ \\
\hline & & E6 & E6 & Putative CCR & NA \\
\hline & & 74 & ORF 74 & Putative CXCR & NA \\
\hline \multirow[t]{18}{*}{$\beta$ Herpesviridae } & \multirow[t]{6}{*}{ Human CMV } & US28 & US28 & CCR3-CX3CR & $\begin{array}{l}\text { Chemokine sequestration } n^{73,74} \text {; smooth muscle } \\
\text { cell chemokinesis }{ }^{75} ; \text { HIV entry } \\
\text { constitutive N F-KB activation }{ }^{79}\end{array}$ \\
\hline & & US27 & US27 & Putative receptor & NA \\
\hline & & UL33 & UL33 & Putative $C C R$ & NA \\
\hline & & UL78 & UL78 & Putative CCR & NA \\
\hline & & UL146 & $\mathrm{vCXC-1}$ & CXC chemokine & $\begin{array}{l}N \text { eutrophil calcium flux; chemotaxis and } \\
\text { degranulation (CXCR2-specific) }{ }^{70}\end{array}$ \\
\hline & & UL147 & $\mathrm{vC} \times \mathrm{C}-2$ & CXC chemokine & NA \\
\hline & \multirow[t]{3}{*}{ Mouse CMV } & $\mathrm{m} 131 / 129$ & $\begin{array}{l}\text { M131/129 } \\
\text { MCK-1/MCK-2 }\end{array}$ & CC chemokine & $\begin{array}{l}\text { Virulence factor; blocks N K and T cell response } \\
\text { to MCMV in vivo; pro-inflammatory early in } \\
\text { infection. Mutant virus } \rightarrow \text { reduced viremia } a^{81,82}\end{array}$ \\
\hline & & UL33 & M33 & Putative CCR & Virulence factor ${ }^{86}$ \\
\hline & & UL78 & M78 & Putative CCR & NA \\
\hline & Simian CMV-derived & ORFs 3-788 & - & Putative CCR & NA \\
\hline & stealth virus & Three O RFs ${ }^{89}$ unnamed & - & CXC chemokine & NA \\
\hline & \multirow[t]{2}{*}{ Rat CMV } & UL33 & R33 & Putative C CR & $\begin{array}{l}\text { Virulence factor (targeting and replication } \\
\text { in salivary gland) }\end{array}$ \\
\hline & & UL78 & $\mathrm{R} 78$ & Putative CCR & Virulence factor \\
\hline & \multirow[t]{3}{*}{ HHV6 } & U 12 & U 12 & CCR & Calcium flux in vitro85 \\
\hline & & U 51 & U 51 & CCR & Downmodulation of RANTES expression ${ }^{91}$ \\
\hline & & U 83 & U 83 & CC chemokine & THP-1 cell chemotaxis ${ }^{92}$ \\
\hline & \multirow[t]{2}{*}{ HHV7 } & U $12^{105}$ & U 12 & Putative CCR & NA \\
\hline & & U $51^{105}$ & U 51 & Putative CCR & NA \\
\hline \multirow[t]{2}{*}{$\alpha$ Herpesviridae } & \multirow[t]{2}{*}{ Marek's disease virus } & MDV003 3 & VIL-8 & CXC chemokine & NA \\
\hline & & MDV0083 & VIL-8 & CXC chemokine & NA \\
\hline \multirow[t]{5}{*}{ Poxviridae } & MCV & MC 148 & $\begin{array}{l}\text { MC } 148 R \\
\text { VMCC-1 }\end{array}$ & CC chemokine & $\begin{array}{l}\text { Blocks neutrophil, monocyte and T cell } \\
\text { chemotaxis induced by multiple CC and } \\
\text { CXC chemokines } \text { S }^{106} \text {; antagonist at CCR2 } \\
\text { and CCR8 } 8^{67} \text {; blocks human hematopoietic } \\
\text { progenitor cell proliferation }{ }^{107}\end{array}$ \\
\hline & $\begin{array}{l}\text { Ortho and leporipox } \\
\text { viruses }\end{array}$ & B29R (vaccinia) & $\begin{array}{l}\text { T1 } \\
35 \mathrm{kD} \text { protein } \\
\mathrm{vCCI} \mathrm{VCKBP} \\
\mathrm{VCBP}-1\end{array}$ & $\begin{array}{l}\text { CC chemokine- } \\
\text { binding protein }\end{array}$ & $\begin{array}{l}\text { Broad spectrum CC chemokine } \\
\text { scavenger }{ }^{95,96} \text {; anti-inflammatory in context } \\
\text { of vaccinia infection and allergic airway } \\
\text { inflammation in guinea pig }\end{array}$ \\
\hline & Myxoma & $\mathrm{T7}$ & $\begin{array}{l}\text { M-T7 } \\
\text { VCBP-2 }\end{array}$ & $\begin{array}{l}\mathrm{CC}, \mathrm{C} \text { and } \mathrm{CXC} \\
\text { chemokine- } \\
\text { binding protein }\end{array}$ & $\begin{array}{l}\text { Broad spectrum C, CXC and CC } \\
\text { chemokine and IFN - } \gamma \text { scavenger }{ }^{95,96} ; \\
\text { anti-inflammatory in context of myxoma } \\
\text { infection }\end{array}$ \\
\hline & Swine poxvirus & $\mathrm{K} 2 \mathrm{R}$ & $\mathrm{K} 2 \mathrm{R}$ & Putative CCR & NA \\
\hline & Capripoxvirus & Q 2/3L & $\mathrm{Q} 2 / 3 \mathrm{~L}$ & Putative CCR & NA \\
\hline \multirow[t]{2}{*}{ Lentiviridae } & \multirow[t]{2}{*}{ HIV } & Tat & Tat & $\begin{array}{l}\mathrm{CC} \text { and } \mathrm{CXC} \\
\text { chemokine mimic }\end{array}$ & $\begin{array}{l}\text { Leukocyte chemotaxis (CCR2, CCR3) })^{47-49} \text {; } \\
\text { CXCR4 blockade }{ }^{44,45}\end{array}$ \\
\hline & & Env & gp120 & Chemokine mimic & HIV entry ${ }^{7,8}$; leukocyte chemotaxisis; apoptosis ${ }^{14,15}$ \\
\hline
\end{tabular}

The following O RFs are syntenic: HHV6 U12, HHV7 U12, HCMV UL33, MCMV M33 and rat CMV M33; HCMV UL78, MCMV M78, rat CMV R78, HHV6 U51 and HHV7 U51. (O RF, open-reading frame; N A, not available; KS, Kaposi's sarcoma; KSHV, Kaposi's sarcoma-associated herpesvirus; G PCR, G protein-coupled receptor; CMV, cytomegalovirus; MCMV, mouse cytomegalovirus; MCV, molluscum contagiosum virus; MCK, murine cytomegalovirus chemokine; RAN TES, regulated upon activation, normal T cell-expressed and secreted; IFN , interferon; IL, interleukin; N F- $\mathrm{KB}$, nuclear factor $\kappa B ; \mathrm{T}_{\mathrm{H}}, \mathrm{T}$ helper; NK, natural killer.) 
Table 2. Classification of viral chemokine mimics.

\begin{tabular}{lll}
\hline Structural subclasses & Functional subclasses & Anti-chemokine subclasses \\
\hline Chemokine homologs & Anti-chemokines & Membrane-associated chemokine scavengers \\
Chemokine receptor homologs & Membrane fusion factors & Secreted chemokine scavengers \\
Unique structures & Growth factors & Chemokine receptor antagonists \\
& Angiogenic factors & \\
& Leukocyte chemoattractants & \\
\hline
\end{tabular}

E N ote that the same molecule may have multiple functions and molecules from different structural subclasses may o carry out the same function.

to tissue factors that modulate the structure of gp120 or its targets or both

을 is still unknown. One example is that viruses that by reporter cell-line cri-

teria are dual-tropic paradoxically may infect primary lymphoid tissue in

a manner that is consistent with monotropism. This was originally sug-

gested in studies that employed coreceptor-selective blocking agents ${ }^{38}$ but

has now been verified using primary lymphoid tissue from a donor

homozygous for CCR $5 \Delta 32^{39}$. A second example is the paradoxical resis-

윽 tance of primary macrophages - which express CXCR4, CCR5 and

은 CD4 to some X4 HIV strains. This may be due, in part, to competition

between CCR5 and CXCR4 for limited amounts of CD4, a competition

won by CCR5, at least in macrophages ${ }^{40}$. Alternatively, a reduced capaci-

๘口 ty of X4 gp120, relative to R5 gp120, for inducing transmembrane signals

윽 in macrophages may be responsible because signaling has been shown to

$\mathbf{Q}$ facilitate early post-fusion steps in viral replication ${ }^{41}$. The signaling path-

๖ way involved has not been clearly identified. However, it may not include

T $\mathrm{G}_{\mathrm{i}}$-type $\mathrm{G}$ proteins, which normally couple to CCR5 and CXCR4, because

$\mathbf{z}$ pertussis toxin-treatment of target cells, which efficiently blocks $\mathrm{G}_{\mathrm{i}}$ sig-

$\bar{\delta}$ naling, has been reported not to affect HIV replication.

\section{Chemokine mimicry by HIV-1Tat}

Biological restrictions on chemokine mimicry by gp120 are also shown by

- the fact that X4 strains can be isolated from only about one-third of $\mathrm{HIV}^{+}$ subjects and almost never until the late stages of disease are reached ${ }^{42}$. This is despite the fact that $\mathrm{CXCR} 4^{+} \mathrm{CCR} 5^{-}$cells represent a much larger subset of $\mathrm{CD}^{+} \mathrm{T}$ cells in blood and lymph node than either CXCR4 ${ }^{-}$ $\mathrm{CCR}^{+}$or $\mathrm{CXCR}^{+} \mathrm{CCR}^{+}$cells ${ }^{38}$. The implication of this subset analysis is that $\mathrm{X} 4$ viral infection may accelerate $\mathrm{CD}^{+} \mathrm{T}$ cell depletion and disease onset. This has been borne out in vitro using peripheral blood mononuclear cells (PBMCs) and primary lymphoid tissue, as well as by epidemiological association studies ${ }^{38,42}$. X4 restriction factors could confer a selective advantage to the virus by increasing the chance of transmission to a new host by prolonging the life of the first host. Such factors may include the relatively low prevalence of $\mathrm{X} 4$ strains in infected populations; the differential distribution of CCR $5^{+}$versus $\mathrm{CXCR}^{+}$target cells in mucosal tissue $^{43}$; and, apropos of the subject of this review, a second HIV-encoded chemokine mimic, the Tat protein ${ }^{44,45}$.

Tat is a transcription factor that is specific for the HIV TAR sequence ${ }^{46}$ but it can also be released from HIV-infected cells and has been detected in serum from a subset of $\mathrm{HIV}^{+}$patients ${ }^{45}$. Among other activities, extracellular Tat can function as a chemokine mimic. It acts as a chemotactic agonist for neutrophils, basophils (via CCR3), mast cells (via CCR3) and monocytes (via CCR2) but as an antagonist at CXCR4; importantly Tat has no activity at CCR $5^{45,47-49}$. Consistent with this, Tat can induce evolution of R5 strains from an X4 inoculum in vitro ${ }^{45}$. Thus, Tat could conceivably contribute to in vivo restriction of $\mathrm{X} 4$ strains by selectively blocking use of CXCR4. Balanced against this are reports that Tat can induce CXCR4 expression ${ }^{50}$ and that a Tat-based vaccine can protect monkeys from SHIV challenge ${ }^{51}$. This suggests that the overriding effect of Tat in vivo may be harmful, not beneficial, perhaps due to its transactivation activity. The SHIV experiment may not test this hypothesis adequately because this virus probably uses CCR5 for infection of target cells. A more significant challenge to the hypothesis is the question of how Tat blockade of CXCR4 might be lifted in late stages of infection to allow emergence of X4 strains.

Compared to chemokines, Tat is similar in length and charge, contains both CXC and CC motifs but lacks other sequence similarities and a chemokine fold. Of note, highly basic small-molecules have been identified that act as specific high-potency antagonists at CXCR4. These include ALX40-4C ${ }^{52}$, a simple nine-residue arginine polymer that was designed to mimic the highly basic ARM (arginine-rich motif) domain of Tat. This may explain the differential specificity of Tat for coreceptors because the extracellular surface of CXCR4 is much more acidic than that of CCR5.

\section{Chemokine mimicry by human herpesvirus 8}

The most common tumor associated with HIV-AIDS is Kaposi's sarcoma (KS), which is widely considered to be an infectious disease caused by HHV8 (also known as Kaposi's sarcoma-associated herpesvirus, or KSHV). Several epidemiologic forms of KS have been recognized, all of which are associated with HHV8 infection. Unlike cancer, KS appears to result from multicentric hyperplasia not metastatic neoplasia ${ }^{53}$. Lesions appear to be growth factor-dependent and are composed of characteristic spindle cells, blood vessels and infiltrating leukocytes. Although molecular mechanisms are still undefined, HHV8 encodes cell cycle-control proteins and multiple cytokines, including three chemokine mimics that are plausible links between the prevailing growth factor and infectious theories of KS pathogenesis. They may also regulate pathogenesis of primary effusion lymphoma and multicentric Castleman's disease, which have both been linked to HIV-AIDS and HHV8.

Most compelling, however, is HHV8 ORF 74 (also referred to as KSHV G protein-coupled receptor, or GPCR, and vGPCR). This constitutively active chemokine receptor ${ }^{54}$ has been shown to induce lesions that are histologically similar to KS when expressed in immunocompetent transgenic mice ${ }^{55}$. The tumors can be reconstituted in wild-type recipients by adoptive transfer of bone marrow cells from ORF 74 transgenic donors. However, receptor transcripts can be detected in only a small subset of tumor cells. This is also the case for primary $\mathrm{KS}$, in which ORF 74 transcripts colocalize with lytic transcripts ${ }^{56}$. This aspect of ORF 74 expression in the context of HHV8 infection is not modeled in the transgenic mouse experiment. However, in both cases, the expression data imply an indirect mechanism of tumorigenesis. In this regard, ORF 74 has been shown, in vitro, to activate host immunoregulatory transcription factors (NF-KB and AP-1). ORF 74 has also been shown to induce expression of: the pro-inflammatory cytokines interleukin 1 (IL1) and TNF; the chemokines IL-8 (also called CXCL8 according to a standard nomenclature ${ }^{1}$ ) and monocyte-chemoattracting protein 1 (MCP-1, or CCL2); and the growth factors basic fibroblast growth factor and vascular endothelial cell growth factor ${ }^{54,57}$. All of these factors have been detected in KS tumors and, together, could coordinate the histological features of KS. Constitutive chemokine induction could even feedback at ORF 74 to modulate its signaling activity. ORF 74 also has oncogenic activity when tested in NIH $3 \mathrm{~T} 3$ cells $^{54}$ but, for the reasons cited above, this activity may not play a role in tumorigenesis. 
HHV8 ORF 74 was apparently copied from the host chemokine receptor CXCR2 but its functional properties are quite different. CXCR2 is not constitutively active, has not been shown to induce cytokine and growth factor expression and binds only the $\mathrm{ELR}^{+} \mathrm{CXC}$ chemokine subset of ORF 74 ligands $^{2}$. CXCR2 is primarily a leukocyte chemotactic receptor but a possible role in tumorigenesis has been suggested by its expression on some tumor cell lines ${ }^{58}$. In addition, CXCR2 has been shown to mediate $\mathrm{CXC}$ chemokine induction of angiogenesis through its expression on E endothelial cells ${ }^{59}$. Thus, both CXCR2 and ORF 74 may regulate tumorigenesis and angiogenesis but by different mechanisms.

An ORF 74 homolog is found in the same chromosomal region in the Telated $\gamma_{2}$ herpesviruses Herpesvirus saimiri (ORF ECRF3) and $\gamma \mathrm{HV} 68$ (ORF 74) ${ }^{60}$, which infect nonhuman primates and mice, respectively. O However, ORF 74 is not conserved in the human $\gamma_{1}$ herpesvirus EpsteinBarr virus. CXC chemokines can induce calcium flux in frog oocytes expressing ECRF $3^{61}$ but its properties in mammalian cells and its role in viral pathogenesis are unknown. The function of $\gamma \mathrm{HV} 68$ ORF 74 has not yet been reported.

HHV8 also encodes three multifunctional CC chemokines, vMIP-I, 윽 vMIP-II and vMIP-III, that act in vitro as leukocyte chemotaxis modula은 tors and HIV-suppressive factors and as angiogenic factors in the chick chorioallantoic membrane assay ${ }^{4,62-64}$. vMIP-I and vMIP-III are chemokine receptor agonists, whereas vMIP-II is a broad-spectrum chemokine wo receptor antagonist. vMIP-III acts selectively at CCR4 and chemoattracts 음 $\mathrm{T}_{\mathrm{H}}$ 2-polarized $\mathrm{T}$ cells. However, the significance of this is unclear because $\mathbf{Q}$ these cells have not been linked yet to KS. vMIP-II blocks signaling of @ CCR1, CCR2, CCR3, CCR5 and CXCR4 and blocks HIV usage of तCR3, CCR5 and CXCR4. vMIP-I also blocks HIV usage of CCR5.

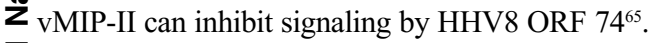

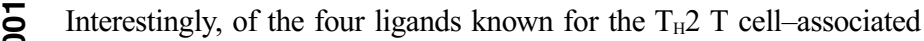
N receptor CCR8, three are viral in origin. These include vMIP-I and vMIP-

(2) II, which are agonists, and MC148R of molluscum contagiosum virus (MCV), which is an antagonist ${ }^{66-68}$. This suggests that this receptor may play quite different roles in HHV8 versus $\mathrm{MCV}$ infection, MCV also being an opportunistic pathogen in HIV-AIDS. Of note, MCV lesions are virtually devoid of leukocyte infiltration suggesting that it deploys powerful anti-inflammatory factors, including - but perhaps not limited toMC148R, whereas KS has prominent leukocyte infiltration.

CCR 8 is expressed in thymus and on $\mathrm{T}_{\mathrm{H}} 2 \mathrm{~T}$ lymphocytes, which suggests the potential therapeutic utility of MC148R in $\mathrm{T}_{\mathrm{H}} 2$-polarized immunologically mediated inflammation. Because vMIP-II has broad target specificity it also has potential as an anti-inflammatory agent. So far it has been shown to be safe and effective in a rat model of glomerulonephritis ${ }^{69}$.

Although HHV8 chemokine mimics may have some role in KS tumorigenesis and HIV disease, they almost certainly serve another more fundamental role in the HHV8 life cycle because this virus almost certainly evolved outside the context of immunosuppression and HIV. With respect to the chemokine receptor agonists, one such role may be to recruit targets to facilitate viral dissemination. Most likely the HIV suppressive activity is accidental, resulting from independent evolution of opposing exploitation and subversion strategies at the same leukocyte targets by HIV and HHV8. It will be important to test the effects of these proteins on viral replication and latency.

\section{Chemokine mimicry in cytomegalovirus}

Human cytomegalovirus (HCMV) can cause severe opportunistic infections that affect multiple organs in immunocompromised hosts, including patients with AIDS. HCMV encodes three chemokine mimics: two CXC chemokine agonists called vCXC- 1 and vCXC- $-2^{70}$ and a
G protein-coupled receptor called US28 (which is specific for multiple $\mathrm{CC}$ chemokines and the $\mathrm{CX} 3 \mathrm{C}$ chemokine fractalkine $)^{71,72}$

In vitro assays have suggested roles for US28 in both immune evasion and viral dissemination. It can scavenge the chemokine RANTES (regulated upon activation, normal $\mathrm{T}$ cell-expressed and secreted) from culture media, which suggests a mechanism to prevent recruitment of leukocytes $^{73,74}$. However, it can also induce chemokine-dependent chemokinesis in vascular smooth muscle cells ${ }^{75}$, which has suggested a role in atherosclerosis consistent with the epidemiologic and physical association of HCMV with that disease. US28 can also enhance cell-cell fusion mediated by different proteins ${ }^{76}$ and could conceivably mediate cell-cell or viruscell adhesion directly by binding fractalkine ${ }^{72}$, an unusual membranebound pro-adhesive chemokine. The latter function would require the presence of US28 in virion membrane, which is not only conceivable but was anticipated by studies with a related viral protein UL33 (see below) ${ }^{77}$. US28 also functions as an HIV coreceptor in some transfected cell lines ${ }^{78}$. Finally, US28 has been shown to be constitutively active in transfected $\mathrm{COS}$ cells and able to induce NF- $\kappa \mathrm{B}$ activation ${ }^{79}$. Which of these activities occur in actual human infection by HCMV is not yet established.

vCXC-1 induces neutrophil chemotaxis ${ }^{70}$, with a potency that is on par with IL-8, and acts selectively at CXCR2, one of the two known IL-8 receptor subtypes ${ }^{2}$. This may explain the association of neutrophils (and mononuclear cells, which also express CXCR2) with HCMV infection. $\mathrm{vCXC}-2$ function has not yet been reported. $\mathrm{vCXC}-1$ and $\mathrm{vCXC}-2$ were detected in low-passage HCMV clinical isolates but not in the attenuated, tissue culture-adapted strain AD169, which suggests that they encode virulence factors.

Neither HCMV chemokine mimic is found in mouse cytomegalovirus (MCMV), which instead encodes a distinct agonistic CC chemokine mimic with a unique structure named $\mathrm{m} 131 / 129$ (also called MCK-1) that is not found in $\mathrm{HCMV}^{80}$. Direct biological analysis of this chemokine using a loss-of-function genetic test has shown its central role in viral dissemination. In particular, normal spread of MCMV to salivary glandwhich occurs late after infection via mononuclear leukocytes, probably monocytes and/or macrophages - is abolished in m131/129 mutants ${ }^{81,82}$. Consistent with this, the chemokine domain of m131/129, induces calcium flux and adherence in murine peritoneal macrophages, although the specific receptors involved have not yet been delineated ${ }^{82} . \mathrm{m131} / 129$ may actually play a complex dual role in pathogenesis, functioning also as an immune evasion factor early in infection because viral seeding of liver and spleen is cleared more rapidly in m131/129 mutants. NK cells mediate early defense against MCMV pathogenesis and this is regulated by the host chemokine MIP-1 $\alpha$, however, direct studies of m131/129 action on these cells have not been reported ${ }^{83}$.

HCMV ORF UL33 $3^{84}$ may also encode a chemokine receptor because it is syntenic with HHV6 ORF U12 ${ }^{85}$, which has been shown to encode a CC chemokine receptor. UL33 is conserved in both mouse and rat CMV. Although their biochemical functions are undefined, targeted disruption of UL33 homologs in both rat and mouse CMV results in reduced viral virulence, which, in part, is due to defective viral spread to salivary gland ${ }^{86,87}$.

Recently the stealth variant of simian CMV has been reported to encode three CXC chemokine homologs and five US28 homologs ${ }^{88,89}$. Together these ORFs account for $7 \%$ of the recognized ORFs in this virus.

\section{Chemokine mimicry in HHV6}

HHV6, which has been implicated as an opportunistic pathogen in HIV disease $^{90}$, has three chemokine system mimics: two are receptors and one is a chemokine agonist. ORF U51 has exceptionally low sequence relatedness to mammalian and other viral chemokine receptors $(<23 \%$ amino acid identity) but, like US28, it binds multiple CC chemokines. It may 
function as an immune evasion molecule but by a unique mechanism: suppression of endogenous RANTES transcription. This has been reported to occur even in the absence of chemokine ligation ${ }^{91}$ and could be viewed as a mechanism for viral spread from the initial site of infection in epithelia. HHV6 also encodes a CC chemokine agonist (ORF U83) ${ }^{92}$ and a second CC chemokine receptor (ORF U12) $)^{85}$ but there is limited information available about their functional roles.

\section{E Secreted chemokine scavengers}

One group of chemokine mimics that are less clearly related to HIV-AIDS

\ّ but are of great conceptual and potential practical importance is the secretస్ ed chemokine scavengers. Soluble chemokine scavengers may be well suited for clinical application in inflammation ${ }^{93,94}$, although issues of $\overline{\mathrm{o}}$ delivery and antigenicity may severely limit the indications.

To date, three structurally unique classes of virally encoded chemokine scavengers have been identified: the $35-\mathrm{kD}$ CC chemokine scavengers of diverse orthopoxviruses and leporipoxviruses; the mixed CC chemokine 을 ind interferon $\gamma$ scavenger of myxoma virus, a rabbit poxvirus; and, the first herpesvirus example, the recently discovered M3 protein of $\gamma$ her윽 pesvirus $68^{95-98}$. M3 binds a broad spectrum of CC and CXC chemokines 온 and blocks chemokine signaling ${ }^{97,98}$. Its relevance to $\mathrm{CXC}$ chemokines is still unclear because, although it binds IL-8 well, it does not appear to bind MIP-2 or KC, the functional mouse counterparts of IL-8. The M3 w sequence is related to another $\gamma \mathrm{HV} 68$ protein M1-which functions as a 윽 latency factor - and the poxvirus serine protease Spi-2, neither of which $\mathbf{Q}$ has been reported yet to bind chemokines.

는 These factors have variable effects on virulence. Deletion of the myxoma virus $35-\mathrm{kD}$ protein M-T1 had no significant effects on disease pro$\mathbf{z}$ gression in or mortality of infected European rabbits. However, $\bar{\delta}$ increased infiltration of leukocytes-particularly monocytes and N macrophages - in primary tissue sites early after infection is observed,

(2) which suggests a role for M-T1 in blocking chemokine-mediated leukocyte mobilization ${ }^{99}$. Nevertheless, viral clearance was not reduced in this experiment, which suggests the importance of concerted action of other viral proteins.

The structure of the $35-\mathrm{kD}$ protein from cowpox has now been elucidated. It is a unique structure with a negatively charged surface that presumably corresponds to the chemokine-binding domain ${ }^{100}$. The chemokine and chemokine receptor mimics with unique structure raise the question of whether nonchemokine host proteins might exist that can activate chemokine receptors. Recently several examples of this have been reported including the $\beta$-defensins, which bind to CCR6 and may provide a link between innate and adaptive immune responses ${ }^{101}$.

It has been reported that CCR5 (and other chemokine receptors) can facilitate infection by myxoma, vaccinia and other poxviruses ${ }^{102}$. If this holds true for variola, which is now being tested, then smallpox will be the leading candidate for the selective pressure that is responsible for fixation of the CCR5 32 HIV-resistance allele in modern Caucasians, the finding that provided proof of principle for the chemokine hypothesis of HIV pathogenesis.

\section{Conclusions}

Why chemokine mimicry is such a common theme in viral pathogenesis is a mystery. The simplest answer, that viruses need to block chemokine action to evade the immune system, clearly applies to only a few of the known examples. The chemokine receptors, in particular, appear to have been adapted to completely new functions. In addition, disease associations such as Kaposi's sarcoma may be misleading with regard to the function of a particular chemokine mimic in the normal viral life cycle. Further study of these diverse molecules holds great promise for improved understanding of viral immunopathogenesis and, in some cases, for clinical application in immunologically mediated diseases.

1. Zlotnik, A.\&Yoshie, O. Chemokines: a new classification system and their role in immunity. Immunity 12, 121-127 (2000).

. Pnion of Pharmacology nomenclature for chemokine receptors. Pharmacol. Rev. 52, 145-176 (2000)

3. Tulman, E. R. et al. The genome of a very virulent Marek's disease virus. J.Virol. 74, 7980-7988 (2000).

4. Boshoff, C . et al. Angiogenic and HIV-inhibitory functions of KSH V-encoded chemokines. Science $\mathbf{2 7 8}$ 290-294 (1997).

5. Spriggs, M. K. O ne step ahead of the game: viral immunomodulatory molecules. Annu. Rev. Immunol. 14 101-130 (1996).

6. McFadden, G. \& Murphy, P. M. Host-related immunomodulators encoded by DN A viruses. Curr. Opin. Microbiol. 3, 371-378 (2000).

. Berger, E.A., Murphy, P. M. \& Farber, J. M. Chemokine receptors as HIV-1 coreceptors: Roles in viral entry, tropism and disease. Ann. Rev. Immunol. 17, 657-700 (1999).

8. Littman, D. R. Chemokine receptors: keys to AIDS pathogenesis? Cell 93, 677-680 (1998),

9. Baba, M. A small-molecule, non-peptide CCR5 antagonist with highly potent and selective anti-HIV-1 activity. Proc. Natl Acad. Sci. USA 96, 5698-5703 (1999)

10. LaC asse, R. A. et al. Fusion-competent vaccines: broad neutralization of primary isolates of HIV. Science 283, 357-362 (1999)

11. W eissman, D. et al. Macrophage-tropic HIV and SIV envelope proteins induce a signal through the CCR5 chemokine receptor. Nature 389, 981-985 (1997).

12. Davis, C. B. et al. Signal transduction due to HIV-1 envelope interactions with chemokine receptors CXCR4 or CCR5. J. Exp. Med. 186, 1793-1798 (1997).

13. lyengar, S., Schwartz, D. H. \& Hildreth, J. E.T cell-tropic HIV gp120 mediates CD 4 and CD 8 cell chemotaxis through CXCR4 independent of CD 4: implications for HIV pathogenesis. J. Immunol. 162 6263-6267 (1999)

14. Hesselgesser, J. et al. N euronal apoptosis induced by HIV-1 gp120 and the chemokine SDF-1 $\alpha$ is mediated by the chemokine receptor CXCR4. Curr. Biol. 8, 595-598 (1998).

15. Herbein, G. et al. A poptosis of CD 8(+)T cells is mediated by macrophages through interaction of HIV gp120 with chemokine receptor CXCR4. Nature 395, 189-194 (1998).

16. W yatt, R. \& Sodroski, J.The H IV-1 envelope glycoproteins: fusogens, antigens, and immunogens. Science 280, 1884-1888 (1998)

17. Berger, E.A. et al. A new classification for HIV-1. Nature 391,240 (1998).

18. Liu, R. et al. Homozygous defect in HIV-1 coreceptor accounts for resistance of some multiply exposed individuals to HIV-1 infection. Cell 86, 367-377 (1996).

19. Samson, M. et al. Resistance to HIV-1 infection in caucasian individuals bearing mutant alleles of the CCR-5 chemokine receptor gene. Nature 382, 722-725 (1996).

20. Dean, M. et al. Genetic restriction of HIV-1 infection and progression to AIDS by a deletion allele of the CKR5 structural gene. Science 273, 1856-1862 (1996).

21. Lu, Z. et al. Evolution of HIV-1 coreceptor usage through interactions with distinct CCR5 and CXCR4 domains. Proc. Natl Acad. Sci. USA 94, 6426-6431 (1997).

22. Michael, N . L. et al. Exclusive and persistent use of the entry coreceptor CXCR4 by human immunodeficiency virus type 1 from a subject homozygous for CCR5 $\Delta 32$. J.Virol. 72, 6040-6047 (1998).

23. Zhang,Y.J. et al. Use of coreceptors other than CCR5 by non-syncytium-inducing adult and pediatric isolates of human immunodeficiency virus type 1 is rare in vitro. J.Virol. 72, 9337-9344 (1998).

24. Lee, B. et al. Influence of the C CR2-V64I polymorphism on human immunodeficiency virus type 1 coreceptor activity and on chemokine receptor function of CCR2b, CCR3, CCR5, and CXCR4. J.Virol. 72 7450-7458 (1998).

25. He, J. et al. CCR3 and CCR5 are co-receptors for HIV-1 infection of microglia. Nature 385, 645-649 (1997).

26. Lee, S. et al. CCR8 on human thymocytes functions as a Human Immunodeficiency Virus type 1 coreceptor. J.Virol. 74, 6946-6952 (2000).

27. Faure, S. et al. Rapid progression to AIDS in HIV+ individuals with a structural variant of the chemokine receptor CX 3CR1. Science 287, 2274-2277 (2000)

28. McD ermott D.A. et al. Technical Comment: Genetic polymorphism in the HIV coreceptor CX3CR1 and risk of HIV disease. Science $\mathbf{2 9 0} 5499$ (2000).

29. Rizzuto, C. D. et al. A conserved HIV gp120 glycoprotein structure involved in chemokine receptor binding. Science 280, 1949-1953 (1998)

30. Farzan, M. et al. Tyrosine sulfation of the amino terminus of C CR5 facilitates H IV-1 entry. Cell $\mathbf{9 6}$ 667-676 (1999).

31. Berson, J. F. \& D oms, R.W. Structure-function studies of the HIV-1 coreceptors. Semin. Immunol. 10 237-248 (1998).

32. Speck, R. F. et al. Selective employment of chemokine receptors as human immunodeficiency virus type 1 coreceptors determined by individual amino acids within the envelopeV3 loop. J.Virol. 71, 7136-7139 (1997).

33. Salzwedel, K., Smith, E. D., D ey, B. \& Berger, E.A. Sequential CD 4-coreceptor interactions in human immunodeficiency virus type 1 Env function: soluble CD 4 activates Env for coreceptor-dependent fusion and reveals blocking activities of antibodies against cryptic conserved epitopes on gp120. J.Virol. 74, 326-333 (2000)

34. Xiao, H. et al. Constitutive cell surface association between CD 4 and CCR5. Proc. Natl Acad. Sci. USA 96 7496-7501 (1999)

35. Lapham, C. K., Zaitseva, M. B., Lee, S., Romanstseva,T. \& Golding, H . Fusion of monocytes and macrophages with HIV-1 correlates with biochemical properties of CXCR4 and CCR5. Nature Med. 5, 303-308 (1999).

36. Vila-C oro,A. J. et al. HIV-1 infection through the CCR5 receptor is blocked by receptor dimerization. Proc. Natl Acad. Sci. USA 97, 3388-3393 (2000).

37. Rodriguez-Frade, J. M. et al. The chemokine monocyte chemoattractant protein-1 induces functional responses through dimerization of its receptor CCR2. Proc. Natl Acad. Sci. USA 96, 3628-3633 (1999).

38. Grivel, J. C.\& Margolis, L. B. CCR5- and CXCR4-tropic HIV-1 are equally cytopathic for their T-cell targets in human lymphoid tissue. Nature M ed. 5, 344-346 (1999).

39. Malkevitch, $\mathrm{N}$. et al. Coreceptor choice and T cell depletion by R5, X 4 and R5X 4 HIV-1 variants in CCR5-deficient (CCR5 32 ) and normal human lymphoid tissue. Virology (in the press, 2001).

40. Lee, S. et al. Coreceptor competition for association with CD 4 may change the susceptibility of human cells to infection with T-tropic and macrophagetropic isolates of human immunodeficiency virus type 1 . J.Virol. 74, 5016-5023 (2000).

41. Arthos, J. et al. CCR5 signal transduction in macrophages by human immunodeficiency virus and simian immunodeficiency virus envelopes. J.Virol. 74, 6418-6424 (2000).

42. Connor, R. I., Sheridan, K. E., Ceradini, D., Choe, S. \& Landau, N. R. C hange in coreceptor use correlates 
with disease progression in HIV-1-infected individuals. J. Exp. M ed. 185, 621-628 (1997).

43. Zhang, L. Q., He,T.,Talal,A.,W ang, G., Frankel, S. S. \& Ho, D. D. In vivo distribution of the human immunodeficiency virus simian immunodeficiency virus coreceptors: CXCR4, CCR3, and CCR5. JVirol. 72 5035-5045 (1998).

44. G hezzi, S. et al. Inhibition of CX CR4-dependent HIV-1 infection by extracellular HIV-1 Tat. Biochem. Biophys. Res. Commun. 270, 992-996 (2000).

45. X iao, H. et al. Selective CXCR4-antagonism by Tat: Implications for in vivo expansion of co-receptor use by HIV-1. Proc. Natl Acad. Sci. USA 97, 11466-11471 (2000).

46. Gallo, R. C. Tat as one key to HIV-induced immune pathogenesis and Tat (correction of Pat) toxoid as an important component of a vaccine. Proc. Natl Acad. Sci. USA 96, 8324-8326 (1999).

47. Albini,A. et al. HIV-1 Tat protein mimicry of chemokines. Proc. Natl Acad. Sci. USA 95, 13153-13158 (1998)

E 48. Benelli, R. et al. Human Immunodeficiency Virus Transactivator Protein (Tat) stimulates chemotaxis, calci-

um mobilization, and activation of human polymorphonuclear leukocytes: Implications for Tat-mediated pathogenesis. J. Infect. Dis. 182 1643-1651 (2000).

j 49. de Paulis, A. et al. Tat protein is an HIV-1-encoded ss-chemokine homolog that promotes migration and up-regulates CCR3 expression on human FcepsilonRI(+) cells. J. Immunol. 165, 7171-7179 (2000).

50. Huang, L., Bosch, l., H ofmann,W., Sodroski, J. \& Pardee,A. B. Tat protein induces human immunodeficiency virus type 1 (HIV-1) coreceptors and promotes infection with both macrophage-tropic and T-lymphotropic HIV-1 strains. J.Virol. 72, 8952-8960 (1998).

을 51. Pauza, C. D. et al.Vaccination with tat toxoid attenuates disease in simian/HIV-challenged macaques. Proc. Natl Acad. Sci. USA 97, 3515-3519 (2000).

52. Doranz, B. J. et al. A small-molecule inhibitor directed against the chemokine receptor CXCR4 prevents its use as an HIV-1 coreceptor. J. Exp. Med. 186, 1395-1400 (1997).

53. Gallo, R. C. The enigmas of Kaposi's sarcoma. Science 282, 1837-1839 (1998)

54. Arvanitakis, L., G eras-Raaka, E.,Varma,A., Gershengorn, M.C.\& Cesarman, E. Human herpesvirus KSHV encodes a constitutively active $\mathrm{G}$-protein-coupled receptor linked to cell proliferation. $\mathrm{N}$ ature $\mathbf{3 8 5}$ 347-350 (1997).

55. Yang, B.T. et al. Transgenic expression of the chemokine receptor encoded by human herpesvirus 8

을 induces an angioproliferative disease resembling Kaposi's Sarcoma. J. Exp. M ed. 191, 445-454 (2000)

을. 56. Kirshner, J. R., Staskus, K., Haase,A., Lagunoff, M. \& Ganem, D. Expression of the open reading frame 74

(G-protein-coupled receptor) gene of Kaposi's sarcoma (KS)-associated herpesvirus: implications for KS pathogenesis. J.Virol. 73, 6006-6014 (1999).

57. Schwarz, M. \& Murphy, P. M. Kaposi's Sarcoma-associated herpesvirus (KSHV) G protein-coupled recep-

tor constitutively activates N F-KB and induces pro-inflammatory cytokine production via a C-terminal signaling determinant. J. Immunol. (Submitted).

58. Moser, B. et al. Expression of transcripts for two interleukin 8 receptors in human phagocytes, lymphocytes and melanoma cells. Biochem. J. 294, 285-292 (1993).

59. Addison, C. L. et al. The CXC chemokine receptor 2,CXCR2, is the putative receptor for $\operatorname{ELR}(+) \mathrm{CXC}$ chemokine-induced angiogenic activity. . Immunol. 165, 5269-5277 (2000).

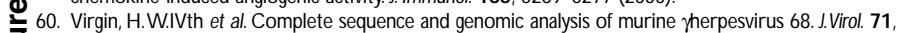
5894-5904 (1997).

61. A huja, S. K. \& Murphy, P. M. Molecular piracy of mammalian interleukin-8 receptor type B by herpesvirus saimiri. J. Biol. Chem. 268, 20691-20694 (1993).

5 62. Dittmer, D.\& Kedes, D. H. Do viral chemokines modulate Kaposi's sarcoma? Bioessays. 20, 367-370 (1998)

N 63. Kledal,T. N . et al. A broad-spectrum chemokine antagonist encoded by Kaposi's sarcoma-associated her-

(2) pesvirus. Science $\mathbf{2 7 7}, 1656-1659$ (1997).

64. Stine, J.T. et al. KSHV-encoded CC chemokine VMIP-III is a CCR4 agonist, stimulates angiogenesis, and selectively chemoattracts TH 2 cells. Blood 95, 1151-1157 (2000).

65. Geras-Raaka, E.,Varma,A., Clark-Lewis, I. \& Gershengorn, M. C. Kaposi's sarcoma-associated herpesvirus (KSHV) chemokine VMIP-II and human SDF-1 $\alpha$ inhibit signaling by KSHV G protein-coupled receptor. Biochem. Biophys. Res. Commun. 253, 725-727 (1998).

66. Endres, M. J., Garlisi, C. G., Xiao, H., Shan, L. \& Hedrick, J.A.The Kaposi's sarcoma-related herpesvirus (KSHV)-encoded chemokine VMIP-I is a specific agonist for the CC chemokine receptor (CCR)8. J. Exp. Med. 189, 1993-1998 (1999).

67. Luttichau, H. R. et al. A highly selective CC chemokine receptor (CCR) 8 antagonist encoded by the poxvirus molluscum contagiosum. J. Exp. Med. 191, 171-180 (2000).

68. Dairaghi, D. J., Fan, R.A., McMaster, B. E., Hanley, M. R. \& Schall,T.J. HHV8-encoded VMIP-I selectively engages chemokine receptor CCR8.Agonist and antagonist profiles of viral chemokines. J. Biol. Chem 274, 21569-21574 (1999)

69. Chen, S. et al. In vivo inhibition of $C C$ and $C X 3 C$ chemokine-induced leukocyte infiltration and attenuation of glomerulonephritis in W istar-Kyoto (W KY) rats by VMIP-II. J. Exp. M ed. 188, 193-198 (1998)

70. Penfold, M. E. et al. Cytomegalovirus encodes a potent alpha chemokine. Proc. Natl Acad. Sci. USA 96, 9839-9844 (1999).

71. Gao, J. L. \& Murphy, P. M. Human cytomegalovirus open reading frame US28 encodes a functional $\beta$ chemokine receptor. J. Biol. Chem. 269, 28539-28542 (1994).

72. Kledal,T. N ., Rosenkilde, M. M. \& Schwartz,T.W. Selective recognition of the membrane-bound CX $3 C$ chemokine, fractalkine, by the human cytomegalovirus-encoded broad-spectrum receptor US28. FEBS Lett. 441, 209-214 (1998)

73. Bodaghi, B. et al. Chemokine sequestration by viral chemoreceptors as a novel viral escape strategy: withdrawal of chemokines from the environment of cytomegalovirus-infected cells. J. Exp. M ed. 188, 855-866 (1998)

74. Billstrom, M.A., Lehman, L.A.\& W orthen G.S. Depletion of extracellular RANTES during human cytomegalovirus infection of endothelial cells. Am. J. Respir. Cell Mol. Biol. 21, 163-167 (1999).

75. Streblow, D. N . et al. The human cytomegalovirus chemokine receptor US28 mediates vascular smooth muscle cell migration. Cell 99, 511-520 (1999).

76. Pleskoff, O .,Treboute, C.\&Alizon, M.The cytomegalovirus-encoded chemokine receptor US28 can enhance cell-cell fusion mediated by different viral proteins. J.Virol. 72, 6389-6397 (1998).

77. Margulies, B. J., Browne, H.\& Gibson, W . Identification of the human cytomegalovirus $G$ protein-coupled receptor homologue encoded by UL33 in infected cells and enveloped virus particles. Virology 225 , 111-125 (1996)

78. Pleskoff, 0 . et al. Identification of a chemokine receptor encoded by human cytomegalovirus as a cofactor for HIV-1 entry. Science 276, 1874-1878 (1997).

79. Casarosa, P. et al. C onstitutive signaling of the human cytomegalovirus-encoded chemokine receptor US28. J. Biol. Chem. 276, 1133-1137 (2001).

80. MacD onald, M. R., Burney, M.W., Resnick, S. B. \&Virgin, H.W. IV. Spliced mRN A encoding the murine cytomegalovirus chemokine homolog predicts a $\beta$ chemokine of novel structure. J.Virol. 73, 3682-3691 (1999).

81. Fleming, P. et al. The Murine Cytomegalovirus chemokine homolog, $\mathrm{ml} 131 / 129$, is a determinant of viral pathogenicity. J.Virol. 73,6800-6809 (1999).

82. Saederup, N ., Lin,Y. C., D airaghi, D. J., Schall,T.J. \& Mocarski, E. S. Cytomegalovirus-encoded $\beta$ chemokine promotes monocyte-associated viremia in the host. Proc. Natl Acad. Sci. USA 96, 10881-10886 (1999).

83. Salazar-Mather,T. P., O range,J. S. \& Biron, C.A. Early murine cytomegalovirus (MCMV) infection induces liver natural killer (N K) cell inflammation and protection through macrophage inflammatory protein $1 \alpha$ (MIP-1 $\alpha$ )-dependent pathways. J. Exp. M ed. 187, 1-14 (1998).

84. Chee, M. S., Satchwell, S. C., Preddie, E.,W eston, K. M. \& Barrell, B. G. Human cytomegalovirus encodes three G protein-coupled receptor homologues. Nature 344, 774-777 (1990).

85. Isegawa, Y., Ping, Z., N akano, K., Sugimoto, N . \& Yamanishi, K. H uman herpesvirus 6 open reading frame U12 encodes a functional $\beta$-chemokine receptor. J.Virol. 72, 6104-6112 (1998).

86. Davis-Poynter, N . J. et al. Identification and characterization of a $\mathrm{G}$ protein-coupled receptor homolog encoded by murine cytomegalovirus. J.Virol. 71, 1521-1529 (1997).

87. Beisser, P. S. et al. The R33 G protein-coupled receptor gene of rat cytomegalovirus plays an essential role in the pathogenesis of viral infection. J.Virol. 72, 2352-2363 (1998).

88. Martin,W.J. Chemokine receptor-related genetic sequences in an african green monkey simian cytomegalovirus-derived stealth virus. Exp. Mol. Pathol. 69, 10-16 (2000).

89. Martin,W. J. Melanoma growth stimulatory activity (MGSA/GRO - $\alpha$ ) chemokine genes incorporated into an African green monkey simian cytomegalovirus-derived stealth virus. Exp. Mol. Pathol. 66, 15-18 (1999)

90. Lusso, P. \& G allo, R. C. Human herpesvirus 6 in AIDS. Immunol.Today. 16, 67-71 (1995).

91. Milne, R. S. et al. RAN TES binding and down-regulation by a novel human herpesvirus- $6 \beta$ chemokine receptor. J. Immunol. 164, 2396-2404 (2000).

92. Zou, P. et al. Human herpesvirus 6 open reading frame U 83 encodes a functional chemokine. J.Virol. 73, 5926-5933 (1999).

93. Liu, L. et al.A viral anti-inflammatory chemokine binding protein, M-T7, reduces intimal hyperplasia after vascular injury. J. Clin. Invest. 105, 1613-1621 (2000)

94. Dabbagh, K. et al. Local blockade of allergic airway hyperreactivity and inflammation by the poxvirusderived pan-CC-chemokine inhibitor VCCI.J. Immunol. 165, 3418-3422 (2000).

95. Lalani,A. S. \& McFadden, G. Evasion and exploitation of chemokines by viruses. Cytok. Growth Factor Rev. 10, 219-233 (1999).

96. Alcami,A. \& Koszinowski, U. H.Viral mechanisms of immune evasion. Immunol.Today. 21 447-455 (2000)

97. Parry, B. C. et al. A broad spectrum secreted chemokine binding protein encoded by a herpesvirus. J. Exp. Med. 191, 573-578 (2000).

98. van Berkel,V. et al. Identification of a $\gamma$ herpesvirus-selective chemokine binding protein that inhibits chemokine action. J.Virol. 74, 6741-6747 (2000).

99. Lalani,A. S. et al. Role of myxoma virus soluble CC-chemokine inhibitor glycoprotein, M-T1, during myxoma virus pathogenesis. Virology 256, 233-245 (1999).

100. Carfi,A., Smith, C.A., Smolak, P. J., McG rew, J. \&W iley, D. C. Structure of a soluble secreted chemokine inhibitor vCCI (p35) from cowpox virus. Proc. Natl Acad. Sci. USA 96, 12379-12383 (1999).

101. Yang, D. et al. $\beta$-defensins: linking innate and adaptive immunity through dendritic and T cell CCR6. Science 286, 525-528 (1999).

102. Lalani,A et al. Use of chemokine receptors by poxviruses. Science 286, 1968-1971 (1999).

103. Bais, C. et al. G-protein-coupled receptor of Kaposi's sarcoma-associated herpesvirus is a viral oncogene and angiogenesis activator. Nature 391, 86-89 (1998).

104. Camarda, G. et al. The equine herpesvirus $2 \mathrm{El}$ open reading frame encodes a functional chemokine receptor.J.Virol. 73, 9843-9848 (1999)

105. N icholas, J. D etermination and analysis of the complete nucleotide sequence of human herpesvirus 7. J.Virol. 70, 5975-5989 (1996)

106. Damon, I., Murphy, P. M. \& Moss, B. Broad spectrum chemokine antagonistic activity of a human poxvirus chemokine homolog. Proc. Natl Acad. Sci. USA 95, 6403-6407 (1998)

107. Krathwohl, M. D., Hromas, R., Brown, D. R., Broxmeyer, H. E., \& Fife, K. H. Functional characterization of the $\mathrm{C}-\mathrm{C}$ chemokine-like molecules encoded by molluscum contagiosum virus types 1 and 2. Proc. Nat Acad. Sci. USA 94, 9875-9880 (1997).p 